\title{
The Fall of Oil Prices and Changes in the Dynamic Relationship between the Stock Markets of Russia and Kazakhstan
}

\author{
Mirzosaid Sultonov
}

Tohoku University of Community Service and Science, 3-5-1 limoriyama, Sakata-shi, Yamagata, 998-8580, Japan

\begin{abstract}
In this paper, we investigate the dynamic relationship between the stock markets of Russia and Kazakhstan and the effect of oil price volatility on both markets. This research differs from the studies of the effect of oil prices on stock markets as it considers the relationship between two post-Soviet transition and developing economies that are highly dependent on the export of oil. The derived results reveal significant interdependence among variations in the stock markets of Russia and Kazakhstan, crude oil prices and the association of falling oil prices with global and Russian crises.
\end{abstract}

Keywords: Financial market, Oil price, Post-soviet economies.

\section{INTRODUCTION}

Russia and Kazakhstan are two large emerging financial markets among the transition economies in the post-Soviet territory. Both countries are dependent on the export of crude oil to a significant degree. Russia ranks as one of the top two oil-producing and exporting countries in the world. Kazakhstan is on the list of the world's top 15 producers and exporters of crude oil ${ }^{1}$. As of 2013, the oil sector accounted for $13.6 \%$ of Gross Domestic Product (GDP) for Russia and $23.8 \%$ of GDP for Kazakhstan (World Bank 2015). Fluctuations in oil prices are expected to affect the key macroeconomic variables of these two countries, including their financial markets.

There is little research on the financial markets of post-Soviet economies, particularly their dynamic linkage and the factors affecting their volatility. Some studies, such as those by Jalolov and Miyakoshi (2005), Hayo and Kutan (2005) and Bhar and Nikolova (2009), have examined the effect of oil prices on the Russian stock market. Using the exponential generalized autoregressive conditionally heteroskedasticity (GARCH) model and monthly data, Jalolov and Miyakoshi (2005) summarized an insignificant influence of oil prices on the Russian stock market. Applying daily returns and the asymmetric GARCH model, Hayo and Kutan (2005) demonstrated

*Address correspondence to this author at the Tohoku University of Community Service and Science, 3-5-1 limoriyama, Sakata-shi, Yamagata, 998-8580, Japan; Tel: 0234-41-1255; Fax: 0234-41-1181; E-mail: sultonov@koeki-u.ac.jp, saidtd@yahoo.com

${ }^{1}$ The rankings are according to the International Energy Agency (IEA) and The World Factbook. the significance of oil prices in predicting Russian stock returns. Estimating the influence of the volatility of stock returns on the volatility of global oil price returns in the economies of Brazil, Russia, India and China (BRIC), Bhar and Nikolova (2009) found no significant impact.

Gomes and Chaibi (2014) used the BEKK ${ }^{2}-G A R C H$ model to show that the volatility of oil markets in the past affects the current stock market volatility of 12 countries, including Kazakhstan. Oskenbayev, Yilmaz and Chagirov (2011) found that oil price volatility, particularly rapid and temporary increases in oil prices, causes a windfall gain effect on the stock index of Kazakhstan.

EDB (2010) and Huseynov (2010) have comprehensive information on the stock markets of Russia and Kazakhstan. Both studies regard the Russian and Kazakhstan stock markets as the most developed in the post-Soviet area. EDB (2010) states that extensive economic ties have promoted interaction between the stock markets in these countries.

According to EDB (2010), the Russian and Kazakhstan stock markets lack strong investor bases. Existing regulatory issues need to be worked out, and market players are less protected than in developed countries. Therefore, potential issuers and professional players in the region prefer to work in international markets. The Russian and Kazakhstan stock markets have to improve the attractiveness of their financial solutions and instruments to compete with other financial markets.

${ }^{2}$ BEKK stands for Baba, Engle, Kraft and Kroner

(c) 2015 Lifescience Globa 
Huseynov (2010) reviewed the market structure of the major stock exchanges in eight post-Soviet countries: Armenia, Azerbaijan, Georgia, Kazakhstan, Kyrgyzstan, Moldova, Uzbekistan and Ukraine. After examining the data, the researcher describes the similarities and differences among these markets that could be improved through structural changes.

In this paper, we investigate the dynamic relationship between the stock markets of Russia and Kazakhstan and the effect of oil price volatility on both markets. This research differs from the studies of the effect of oil prices on stock markets as it considers the relationship between two post-Soviet transition and developing economies that are highly dependent on the export of oil. In addition, we assess and describe changes in the dynamic relationship among the mentioned stocks markets and crude oil prices over a period with two sharp falls in the price of oil, one coinciding with the global financial crisis and one with the Russian crisis.

\section{METHODOLOGY}

We estimated the parameters of dynamic conditional correlation (DCC) bivariate and multivariate generalized autoregressive conditionally heteroskedastic (MGARCH) models. The conditional variances were modelled as a univariate GARCH model (Bollerslev 1986). The conditional covariances were modelled as nonlinear functions of the conditional variances (Engle 2002). The model can be written as

$y_{t}=C x_{t}+\varepsilon_{t}$

$\varepsilon_{t}=H_{t}^{1 / 2} v_{t}$

$H_{t}=D_{t}^{1 / 2} R_{t} D_{t}^{1 / 2}$

$R_{t}=\operatorname{diag}\left(Q_{t}\right)^{-1 / 2} Q_{t} \operatorname{diag}\left(Q_{t}\right)^{-1 / 2}$

$Q_{t}=\left(1-\lambda_{1}-\lambda_{2}\right) R+\lambda_{1} \tilde{\varepsilon}_{t-1} \tilde{\varepsilon}_{t-1}^{\prime}+\lambda_{2} Q_{t-1}$

where $y_{t}$ is an $\mathrm{m} \times 1$ vector of dependent variables, $\mathrm{C}$ is an $\mathrm{m} \times \mathrm{k}$ matrix of parameters, $x_{t}$ is a $\mathrm{k} \times 1$ vector of independent variables that may contain lags of dependent variables, $H_{t}^{1 / 2}$ is the Cholesky factor of the time-varying conditional covariance matrix $H_{t}, v_{t}$ is an $\mathrm{m} \times 1$ vector of innovations and $D_{t}$ is a diagonal matrix representing the conditional volatilities from Equation 6.

$\sigma_{i, t}^{2}=\omega_{i}+\sum_{j=1}^{p_{i}} a_{j} \varepsilon_{i, t-j}^{2}+\sum_{j=1}^{q_{i}} \beta_{j} \sigma_{i, t-j}^{2}$

$\tilde{\varepsilon}_{t}$ is an $\mathrm{m} \times 1$ vector of standardized residuals, $\lambda_{1}$ and $\lambda_{2}$ are parameters of the dynamics of conditional quasi correlations and $\lambda_{1}$ and $\lambda_{2}$ are non-negative and satisfy the $0 \leq \lambda_{1}+\lambda_{2}<1$ condition.

We modelled the conditional means of the returns as third and first-order vector autoregressive (VAR) processes and the conditional covariances as DCC $M G A R C H$ processes in which the variance of each disturbance term follows a $\operatorname{GARCH}(1,1)$ process. We used the Schwarz Bayesian information criterion (SBIC) to select the lag order for VAR and applied the Ljung-Box $Q$ test to define the parameters of $G A R C H$.

\section{DATA}

The daily data covered the period from October 4 , 2007 to May 18, 2015. We used logarithmic return series of closing values of Russian and Kazakhstan stock indices (Moscow Interbank Currency Exchange (MICEX) and Kazakhstan Stock Exchange (KASE)) and the price of crude oil (West Texas Intermediate (WTI)) in estimations. We omitted weekends and holidays. The Moscow Exchange and the Kazakhstan Stock Exchange were sources of data for the stock indices. Datastream was the source of data for the price of crude oil.

Table 1 shows the descriptive statistics for the indices' returns. All variables have the mean close to zero. The Jarque-Bera test rejects the null hypothesis of normal distribution of the observed series. The null hypothesis of no autoregressive conditional heteroskedasticity $(\mathrm{ARCH})$ effects is rejected at the $1 \%$ significance level. The test results justify the use of GARCH-type models.

Table 1: Descriptive Statistics for Indices' Returns

\begin{tabular}{|c|c|c|c|c|c|c|}
\hline Variable & Mean & Std. Dev. & Skewness & Kurtosis & Jarque-Bera & ARCH effect \\
\hline \hline MICEX & -0.00003 & 0.02458 & -0.21226 & 22.1605 & $26,000.0^{\star * *}$ & $241.031^{* * *}$ \\
\hline KASE & -0.00066 & 0.02165 & 1.10971 & 28.4086 & $46,000.0^{* * *}$ & $79.8670^{* * *}$ \\
\hline WTI & -0.00018 & 0.02728 & 0.04142 & 11.7880 & $5,407.00^{* *}$ & $270.880^{* * *}$ \\
\hline
\end{tabular}

Notes: ${ }^{* * *}$ in Jarque-Bera test indicate that the null hypothesis of "normal distribution" is rejected at $1 \%$ significant level. ARCH effect reports LM test for ARCH(5) disturbance. ${ }^{* * *}$ mean the rejection of null hypothesis of "no ARCH effect" at $1 \%$ significant level. 
We applied the augmented Dickey-Fuller (ADF) test to examine the return series for the presence of unit root. The results of the ADF test for the unit root in indices' returns resulted in the rejection of the null hypothesis regarding the presence of unit root.

Table 2: Results of Stationary Test

\begin{tabular}{|c|c|c|}
\hline Variable & ADF (a constant) & ADF (a constant and trend) \\
\hline \hline MICEX & $-7.526^{\star \star *}$ & $-7.580^{\star \star \star}$ \\
\hline KASE & $-6.768^{\star \star *}$ & $-6.781^{\star \star \star}$ \\
\hline WTI & $-7.229^{\star \star *}$ & $-7.229^{\star \star \star}$ \\
\hline
\end{tabular}

Notes: The maximum number of lags for ADF test selected by Schwarz information criterion (SIC) was $24 .{ }^{* \star *}$ mean smaller than the critical value at $1 \%$ significant level.

\section{EMPIRICAL RESULTS}

The results of the bivariate $\operatorname{GARCH}(1,1)$ model in Table 3 show that MICEX returns are not explained by its lagged returns or the lagged returns of KASE. KASE returns are explained by its previous day's returns and the lagged returns of MICEX.

Table 3: Results of the Bivariate DCC-GARCH Model

\begin{tabular}{|c|c|c|}
\hline & MICEX & KASE \\
\hline \multicolumn{3}{|c|}{ Mean } \\
\hline $\mathrm{KASE}_{t-1}$ & $-0.019(0.029)$ & $-0.085^{\star * *}(0.031)$ \\
\hline $\operatorname{KASE}_{t-2}$ & $0.046(0.029)$ & $-0.018(0.030)$ \\
\hline $\operatorname{KASE}_{t-3}$ & $-0.007(0.029)$ & $0.027(0.028)$ \\
\hline MICEX $_{t-1}$ & $-0.029(0.028)$ & $0.195^{* \star *}(0.024)$ \\
\hline MICEX $_{t-2}$ & $-0.007(0.029)$ & $0.085^{\star \star *}(0.024)$ \\
\hline MICEX $_{t-3}$ & $0.007(0.028)$ & $0.057^{* *}(0.023)$ \\
\hline Constant & $0.001^{* *}(0.000)$ & $-0.000(0.000)$ \\
\hline \multicolumn{3}{|c|}{ Variance } \\
\hline$\alpha$ & $0.101^{\star \star \star}(0.015)$ & $0.140^{* * *}(0.019)$ \\
\hline$\beta$ & $0.881^{\star * *}(0.016)$ & $0.812^{* * *}(0.022)$ \\
\hline$\omega$ & $0.000^{* * *}(0.000)$ & $0.000^{\star \star \star}(0.000)$ \\
\hline \multicolumn{3}{|c|}{ DCC } \\
\hline$\lambda_{1}$ & \multicolumn{2}{|c|}{$0.015^{\star * *}(0.003)$} \\
\hline$\lambda_{2}$ & \multicolumn{2}{|c|}{$0.981^{* * *}(0.004)$} \\
\hline \multicolumn{3}{|c|}{ Diagnostic } \\
\hline$Q^{2}(10)$ & 4.991 & 3.3153 \\
\hline
\end{tabular}

Notes: The numbers in parentheses are standard errors. Squared $Q(10)$ is the Ljung-Box Q statistics for the null hypothesis that there is no autocorrelation up to orders 10 for squared standardized residuals. ${ }^{* *}$ and ${ }^{* * *}$ mean significance at the $5 \%$ and $1 \%$ levels. The values of $\omega$ are positive and bigger than 0 .
The estimates in the variance equation are all statistically significant at the $1 \%$ level. Conditional variances of indices' returns are influenced by their own previous day's information and variances.

Table 4 shows the results of the multivariate GARCH $(1,1)$ model with the indices' returns of KASE, MICEX and WTI as dependent variables. MICEX returns are not explained by its own or KASE's and WTI's previous days' returns. KASE returns are explained by its previous day's returns and the previous day's returns of MICEX and WTI. WTI returns are explained by its previous day's returns. Like the bivariate model, conditional variances of indices' returns are influenced by their own previous day's information and variances. The values of $\alpha, \beta, \omega, \lambda_{1}$ and $\lambda_{2}$ satisfy the restriction conditions of $\alpha>1, \beta>1$, $\omega>1, \alpha+\beta<1$ and $0 \leq \lambda_{1}+\lambda_{2}<1$. The magnitudes of the lambda parameters indicate that conditional correlations are not constant, and the evolution of the conditional correlations depends more on their past values than on lagged residuals' innovations. The Ljung-Box statistics do not reject the null hypothesis of no serial correlation in standardized residuals, which confirms that GARCH-type models are appropriate.

Table 4: Results of the Multivariate DCC-GARCH Model

\begin{tabular}{|c|c|c|c|}
\hline & MICEX & KASE & WTI \\
\hline \multicolumn{4}{|c|}{ Mean } \\
\hline KASE $_{t-1}$ & $-0.008(0.027)$ & $-0.061^{* *}(0.029)$ & $-0.021(0.030)$ \\
\hline MICEX $_{t-1}$ & $-0.034(0.028)$ & $0.138^{* * *}(0.025)$ & $0.015(0.029)$ \\
\hline $\mathrm{WTI}_{t-1}$ & $0.019(0.019)$ & $0.095^{\star * *}(0.019)$ & $\begin{array}{c}-0.081^{* * *} \\
(0.027)\end{array}$ \\
\hline Constant & $0.001^{* *}(0.000)$ & $0.000(0.000)$ & $0.001(0.000)$ \\
\hline \multicolumn{4}{|c|}{ Variance } \\
\hline$\alpha$ & $0.102^{\star * \star}(0.015)$ & $0.135^{\star \star *}(0.020)$ & $0.073^{\star \star \star}(0.013)$ \\
\hline$\beta$ & $0.876^{\star \star \star}(0.016)$ & $0.823^{\star \star *}(0.022)$ & $0.911^{* \star *}(0.016)$ \\
\hline$\omega$ & $0.000^{\star \star *}(0.000)$ & $0.000^{* * *}(0.000)$ & $0.000^{* * *}(0.000)$ \\
\hline \multicolumn{4}{|c|}{ DCC } \\
\hline$\lambda_{1}$ & \multicolumn{3}{|c|}{$0.015^{* * *}(0.002)$} \\
\hline$\lambda_{2}$ & \multicolumn{3}{|c|}{$0.982^{* \star *}(0.002)$} \\
\hline \multicolumn{4}{|c|}{ Diagnostic } \\
\hline$Q^{2}(10)$ & 4.368 & 2.820 & 5.170 \\
\hline
\end{tabular}

Notes: The numbers in parentheses are standard errors. Squared Q (10) is the Ljung-Box Q statistics for the null hypothesis that there is no autocorrelation up to orders 10 for squared standardized residuals. ** and ${ }^{* *}$ mean significance at the $5 \%$ and $1 \%$ levels. The values of $\omega$ are positive and bigger than 0 . 


\section{MICEX_KASE}

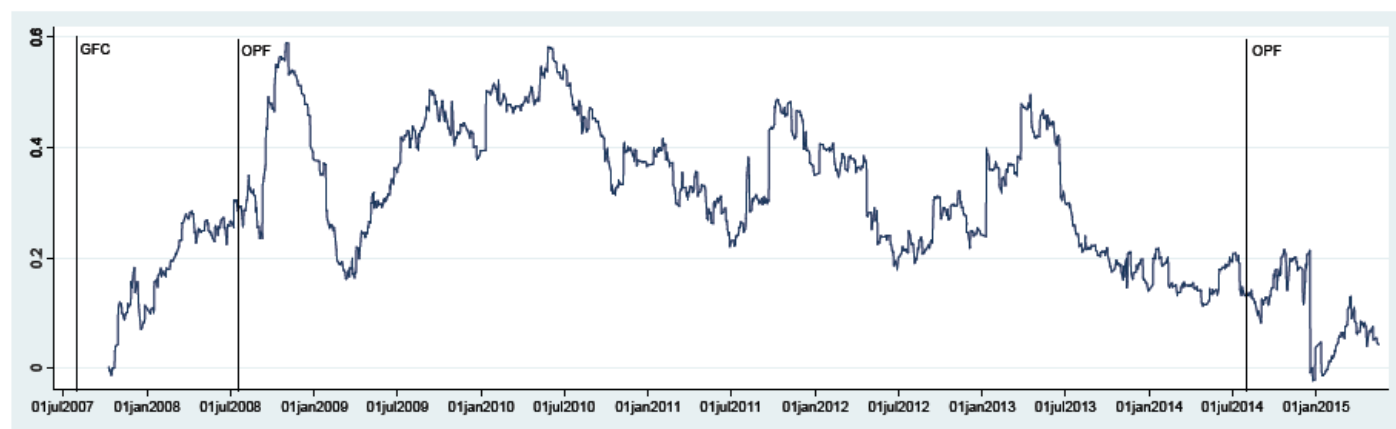

\section{MICEX WTI}

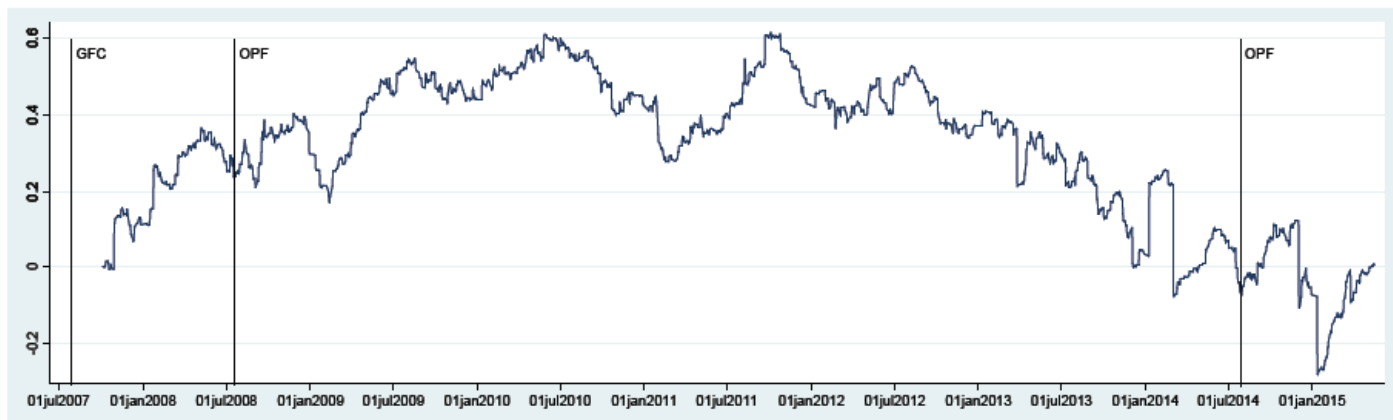

\section{KASE_WTI}

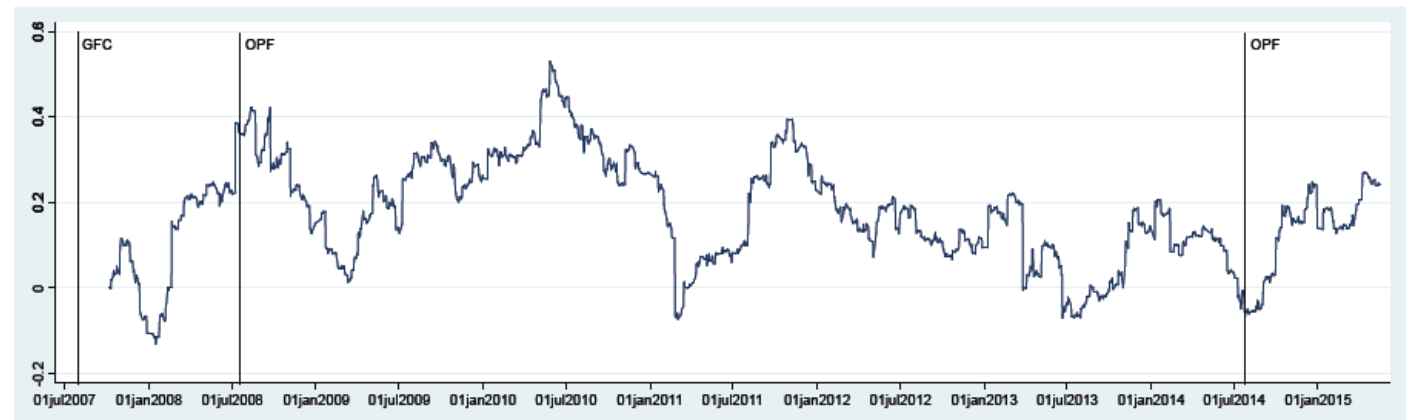

Notes: GFC is for the Global Financial Crisis and OPF for crude oil price fall.

Figure 1: Dynamic Conditional Correlation between Indices' Returns.

Figure 1 depicts dynamic conditional correlations from the estimated models. The correlations range from -0.02 to 0.59 between MICEX and KASE, from -0.28 to 0.61 between MICEX and WTI, and from -0.13 to 0.53 between KASE and WTI. The high volatility of conditional correlations is observed between indices' returns.

Conditional correlations between indices' returns are high, indicating interdependence between the stock markets and their dependence on crude oil price. Conditional correlations have an increasing trend for the period of the global financial crisis of 2007-2008, which coincided with the increase in the price of oil.
For the period when oil prices fell in July to December of 2008, conditional correlations between MICEX and the other two indices' returns have increasing trends. The conditional correlation between KASE and WTI has a decreasing trend for the period mentioned. Conditional correlations between MICEX and the other two indices are lower after the 2014 fall in the price of oil but have a shape similar to the shapes after the 2008 fall in the price of oil. The conditional correlation between KASE and WTI has an increasing trend after the second fall in the price of oil. The relationship of MICEX with other indices is less volatile and negligible for the period when the price of oil fell in 
2014, and the correlation with WTI index returns is mostly negative.

The 2008 fall in the price of oil coincided with the global financial crisis, and the 2014 fall in the price of oil coincided with the Russian crisis. The global financial crisis threatening the collapse of large financial institutions caused stock markets and commodity prices to fall worldwide, including MICEX, KASE and WTI indices. The financial crisis in Russia was the result of the fall in the price of oil, economic sanctions and the devaluation of the Russian rouble.

\section{CONCLUSION}

In this paper, we investigated the dynamic relationship between the stock markets of Russia and Kazakhstan and the effect of oil price volatility on both markets. The results show a positive relationship between stock returns and between stock and oil price indices' returns. Dynamic correlations between MICEX and the other two indices are higher compared with the dynamic correlation between KASE and WTI. MICEX has a high dynamic correlation with increasing trends with KASE and WTI for the period when oil prices fell coincident with the global financial crisis and lower dynamic correlations with decreasing trends for the period when oil prices fell coincident with the Russian crisis. KASE has a high dynamic correlation with decreasing trends with WTI for the period when oil prices fell coincident with the global financial crisis and a lower dynamic correlation with increasing trends for the period when oil prices fell coincident with the Russian crisis.

The overall findings of this study reveal significant interdependence among variations in the stock markets of Russia and Kazakhstan, crude oil prices and the association of falling oil prices with global and Russian crises. The interdependence of the stock markets might be explained by the extensive economic ties between Russia and Kazakhstan, as mentioned by EDB (2010). The significant relationship between stock markets and oil prices are preconditioned by these economies' high degree of reliance on oil exports. Differences in the dynamic correlations during the period of sharp falls in the prices of oil coinciding with the global financial crisis and the Russian crisis are related to volatility in other macroeconomic variables, such as exchange rates, which are not covered in this paper but are a future direction for our research. These findings may have important implications for investors seeking portfolio diversification in oil-exporting post-Soviet emerging financial markets. These markets have attempted to become open, competitive trading floors complying with international standards for financial markets. The findings of the academic researches which highlight trends in these markets, the interdependence between them and the factors affecting their development are important for local and foreign market participants.

\section{REFERENCE}

Bhar, Ramaprasad and Biljana Nikolova. 2009. "Oil Prices and Equity Returns in the BRIC Countries." The World Economy, 32(7):1036-1054. http://dx.doi.org/10.1111/j.1467-9701.2009.01194.x

Bollerslev, Tim. 1986. "Generalised Autoregressive Conditional Hetroscedasticity." Journal of Econometrics 31:307-327. http://dx.doi.org/10.1016/0304-4076(86)90063-1

EBD. 2010. The Stock Markets of Russia and Kazakhstan: Prospects for Integration, EDB Industry Report No. 10 (Almaty: EDB).

Engle F. Robert. 2002. "Dynamic Conditional Correlation: A Simple Class of Multivariate Generalized Autoregressive Conditional Hetroscedasticity Models." Journal of Business and Economic Statistics 20(3):339-350. http://dx.doi.org/10.1198/073500102288618487

Gomes, Mathieu and Anissa Chaibi. 2014. "Volatility Spillovers between Oil Prices and Stock Returns: A Focus on Frontie Markets." The Journal of Applied Business Research 30(2):509-526.

Hayo, Bernd and Ali M. Kutan. 2005. "The Impact of News, Oi Prices, and Global Market Developments on Russian Financial Markets." Economics of Transition, 13(2):373-393. http://dx.doi.org/10.1111/j.1468-0351.2005.00214.x

Huseynov Fariz. 2010. "Review of CIS stock markets: Future perspectives." Transition Studies Review, 17: 63-79. http://dx.doi.org/10.1007/s11300-010-0136-4

Jalolov, Mirzosharif and Tatsuyoshi Miyakoshi. 2005. "Who Drives the Russian Financial Markets?" The Developing Economies 43(3): 374-395. http://dx.doi.org/10.1111/j.1746-1049.2005.tb00950.x

Oskenbayev, Yessengali, Yilmaz, Mesut and Dauren Chagirov. 2011 "The Impact of Macroeconomic Indicators on Stock Exchange Performance in Kazakhstan." African Journal of Business Management 5(7): 2985-2991. DOI: 10.5897/AJBM10.1480

World Bank. 2015. World Development Indicators: Contribution of Natural Resources to Gross Domestic Product. Retrieved May 1, 2015 (http://wdi.worldbank.org/table/3.15).

(c) 2015 Mirzosaid Sultonov; Licensee Lifescience Global.

This is an open access article licensed under the terms of the Creative Commons Attribution Non-Commercial License (http://creativecommons.org/licenses/by-nc/3.0/) which permits unrestricted, non-commercial use, distribution and reproduction in any medium, provided the work is properly cited. 